\title{
Insecticidal effect of a fungicide containing polyoxin $B$ on the larvae of Bombyx mori (Lepidoptera: Bombycidae), Mamestra brassicae, Mythimna separata, and Spodoptera litura (Lepidoptera: Noctuidae)
}

\author{
Toru Arakawa, * Fumiko Yukuhiro and Hiroaki NodA \\ National Institute of Agrobiological Sciences (NIAS); Tsukuba, Ibaraki 305-8634, Japan \\ (Received 11 September 2007; Accepted 30 November 2007)
}

\begin{abstract}
The insecticidal effect of a water-soluble powder of Polyoxin AL, a fungicide that inhibits chitin synthase, on the larvae of Bombyx mori, Mamestra brassicae, Mythimna separata, and Spodoptera litura was examined. After the fungicide was mixed in diet and applied orally, all the larvae of S. litura, M. separata, and M. brassicae died at the molting stage at polyoxin levels of $0.03,0.1$, and $0.3 \%$ (wt/wt), respectively. A morphological study with $S$. litura showed that the larvae to which Polyoxin AL was orally applied failed to form a new cuticle. The median lethal concentration $\left(\mathrm{LC}_{50}\right)$ of Polyoxin AL in $S$. litura $3 \mathrm{rd}$ stadium larvae was approximately $0.02 \%$. Polyoxin AL had little effect on $B$. mori, even at $0.3 \%$ in the diet. The standard chemicals polyoxin $\mathrm{B}$, polyoxin $\mathrm{D}$, and nikkomycin $\mathrm{Z}$ were applied orally to $S$. litura 3rd stadium larvae. All the larvae were killed after exposure to $0.005 \%$ polyoxin B and $0.015 \%$ nikkomycin Z. Polyoxin D, however, had no effect even at $0.015 \%$. Polyoxin B and D were injected into the hemocoel of $S$. litura and B. mori with a syringe. The responses of these insects were quite different. In $S$. litura, both the chemicals inhibited metamorphosis. In B. mori, polyoxin B inhibited the larval molt, whereas polyoxin D had no effect. Body surface treatment with 1\% (wt/vol) Polyoxin AL resulted in a failure to molt in both species.
\end{abstract}

Key words: Chitin synthase inhibitor; molting inhibition; nikkomycin; polyoxin

\section{INTRODUCTION}

Chitin, an important biopolymer in insects, is an essential component of epidermal cuticular exoskeleton and of intestinal peritrophic membrane (Merzendorfer and Zimock, 2003). Chitin biosynthesis is therefore an attractive target of insecticides (Cohen, 1987). Benzoylphenyl ureas are practically used as insect growth regulators (IGRs) that inhibit insect chitin synthesis (Cohen, 1987). Polyoxins and nikkomycins are Streptomyces-derived antibiotics that inhibit fungal and insect chitin synthases (Hori et al., 1971; Cohen, 1987; Decker et al., 1991). Effects of these antibiotics on insect chitin metabolism have been studied by four methods: tissue culture, the cell-free system, hypodermic injection, and oral application.

Tissue culture. A piece of integument excised from a living specimen was incubated in a culture medium containing the antibiotic. Polyoxin D in- hibited the chitin synthesis in the cultured tissue of lepidopteran (Nishioka et al., 1979; Kaska et al., 1980; Kitahara et al., 1983; Gelman and Borkovec, 1986), blattodean (Sowa and Marks, 1975; Nakagawa et al., 1993), and dipteran (van Eck, 1979; Becker, 1980; Mayer et al., 1980a; Turnbull and Howells, 1982) insects.

Cell-free system. Effects of the antibiotics on chitin synthesis were examined by using the homogenates of tissues. Polyoxin B and D, and nikkomycins inhibited chitin synthesis in lepidopteran (Cohen and Casida, 1982) and dipteran (Mayer et al., 1980b) insects.

Hypodermic injection. Effects of the antibiotics on insects were examined by injecting the antibiotics into the hemocoel hypodermically. Polyoxin A and D killed lepidopteran (Gijswijt et al., 1979) and orthopteran (Vardanis, 1978) insects by inhibiting molting.

Oral application. Insects were fed with a diet

\footnotetext{
* To whom correspondence should be addressed at: E-mail: arak@nias.affrc.go.jp
} DOI: $10.1303 / \mathrm{aez} .2008 .173$ 
containing the antibiotics. The antibiotics did not always harm the insect. Polyoxin D had no effect on lepidopteran (Gijswijt et al., 1979) and dipteran (Shahabuddin et al., 1995) insects. On the other hand, the same antibiotic killed dipteran insects (Turnbull and Howells, 1982; Binnington, 1985; Tellam and Eisemann, 2000). Nikkomycin Z killed coleopteran (Schlüter, 1982) and dipteran (Tellam et al., 2000) insects and mites (Holst et al., 1978; Mothes and Seitz, 1982). These studies showed that polyoxins and nikkomycins effectively inhibit insect chitin synthesis when they act on the tissue directly, but are not always effective when applied orally. Cohen (1987) stated that these antibiotics are effective fungicides but are poor insect-control agents.

A review of the above reports indicated the following two findings: 1) polyoxin D toxicity has been studied extensively to date, unlike other polyoxin derivatives and 2) lepidopteran insects, which include many important agricultural pests, are not killed by orally applied polyoxins and nikkomycins. In the present study, the oral toxicities of polyoxin $\mathrm{B}$ and $\mathrm{D}$, nikkomycin $\mathrm{Z}$, and a water-soluble powder of Polyoxin AL were examined in lepidopteran insects. It was shown that Polyoxin AL and polyoxin B killed the larvae of Mamestra brassicae, Mythimna separata, and Spodoptera litura by inhibiting molting. Bombyx mori was more resistant to Polyoxin AL than were the other insects.

\section{MATERIALS AND METHODS}

Insects and chemicals. Egg masses of the cabbage armyworm (M. brassicae), rice armyworm (M. separata), and common cutworm ( $S$. litura) were kindly supplied by Dr. K. Tateishi at this institute (NIAS). These insects have been cultured in the laboratory for more than $20 \mathrm{y}$. Eggs of the silkworm B. mori (Ariake) were supplied from NIAS Genebank. The larvae of these insects were reared on an artificial diet (Silkmate 2S; Nosan Corporation Co., Ltd.) at $25^{\circ} \mathrm{C}$ with a long-day photoperiod (16L : 8D). Polyoxin AL water-soluble powder (designated as Polyoxin AL) consisting of $50 \%$ polyoxin complex (mainly polyoxin B) and $50 \%$ additives was purchased from Kaken Pharmaceutical Co., Ltd. Polyoxin B standard (designated as Polyoxin B st.) containing 29\% polyoxin B was obtained from Kanto Chemical Co., Ltd. Polyoxin D
(99.6\% purity) and nikkomycin Z (>97\% purity) were purchased from Funakoshi Co., Ltd. and Sigma Co., Ltd., respectively.

Dose response of lepidopteran species to Polyoxin AL. Polyoxin AL was dissolved in distilled water (DW) at 5\% (wt/wt) and then mixed with a diet to make the indicated final concentration of the formulation ( $\%$ in $w t / w t)$ in each experiment. The mixture was kneaded well with a spatula. Throughout the study, all diets including chemicals were prepared in the same way. Pharate-3rd stadium larvae of $M$. brassicae, M. separata, and S. litura were placed in cups with a diet containing Polyoxin AL from 0.03 to $0.3 \%, 0.03$ to $0.1 \%$, and 0.01 to $0.1 \%$, respectively, and reared at $25^{\circ} \mathrm{C}$. After $48 \mathrm{~h}$, all the larvae developed to the pharate-4th stadium and were switched to a normal diet and then reared for additional $4 \mathrm{~d}$. Newly exuviated $B$. mori 3 rd stadium larvae, not in the pharate stage, were fed with a diet containing Polyoxin AL at 0.1 and $0.3 \%$. After $5 \mathrm{~d}$, all the larvae developed to the pharate4th stadium or just molted to the 4th stadium and were switched to a normal diet and then reared for additional $7 \mathrm{~d}$. The number of larvae that developed to the next stadium and to the stadium after the next were examined. Throughout the present study, larval development was followed in the same way unless otherwise mentioned.

Toxicity of Polyoxin AL on 3rd, 4th, 5th, and 6th stadium $S$. litura larvae. Pharate-3rd, -4 th, -5 th, and -6 th stadium $S$. litura larvae were reared on a diet containing $0.1 \%$ Polyoxin AL for 24 or $48 \mathrm{~h}$ at $25^{\circ} \mathrm{C}$. They were then switched to a normal diet without the fungicide. Larval development was followed as mentioned above. For 6th stadium larvae, only pupation was examined.

Median lethal concentration $\left(\mathrm{LC}_{50}\right)$ of Polyoxin AL. Pharate-3rd stadium $S$. litura larvae were reared with a diet series containing Polyoxin $\mathrm{AL}$ from 0.0105 to $0.03 \%$ at $25^{\circ} \mathrm{C}$. After $48 \mathrm{~h}$, the larvae were switched to a normal diet and then reared for additional $4 \mathrm{~d}$. Thirty specimens were used for each concentration of Polyoxin AL. The number of larvae that died during ecdysis to the next stadium or failed to grow after the ecdysis was examined. $\mathrm{LC}_{50}$ was determined by the computer program PriProbit (version 1.63) developed by Dr. M. Sakuma, Kyoto University.

Morphology of $S$. litura after the oral application of Polyoxin AL. Pharate-3rd stadium S. litura 
larvae were reared with a diet containing $0.3 \%$ Polyoxin $\mathrm{AL}$ at $25^{\circ} \mathrm{C}$. After 48 and $72 \mathrm{~h}$, the integument and the midgut were excised from the larvae, and fixed in $2.5 \%$ (wt/wt) glutaraldehyde at $4^{\circ} \mathrm{C}$ for $2 \mathrm{~h}$, dehydrated in ethanol series, and then embedded in Spurr's resin. A section of approximately $1 \mu \mathrm{m}$ thickness was stained with $1 \%$ (wt/wt) toluidine blue and examined by optical microscope.

Relationship between the lethal effect of Polyoxin AL and development. Pharate-3rd stadium larvae were reared with a normal diet for $24 \mathrm{~h}$ at $25^{\circ} \mathrm{C}$. Next, the mid-3rd stadium larvae that were feeding actively on the diet were switched to a diet containing $0.1 \%$ Polyoxin AL. After $24 \mathrm{~h}$, all the larvae developed to the pharate-4th stadium and were switched to a normal diet without Polyoxin $\mathrm{AL}$ and reared. These larvae ingested $0.1 \%$ Polyoxin AL during the latter half in the 3rd stadium. Control larvae were fed with $0.1 \%$ Polyoxin $\mathrm{AL}$ during the former half in the 3rd stadium and then switched to a normal diet as in the above experiment. Fifty specimens were used for each assay, and their development was followed.

Body surface treatment with Polyoxin AL. Pharate-3rd stadium S. litura larvae were reared with a diet at $25^{\circ} \mathrm{C}$. After 24 and $48 \mathrm{~h}$, larvae from 0 to $24 \mathrm{~h}$ and from 24 to $48 \mathrm{~h}$ into the $3 \mathrm{rd}$ stadium were obtained. The larvae were immersed in $1 \%$ (wt/vol) Polyoxin AL in DW for a few seconds with forceps and then left on filter paper until their body surface dried. $B$. mori larvae just after ecdysis and $24,48,72$, and $96 \mathrm{~h}$ into the 3rd stadium were treated with Polyoxin AL similarly. The treated larvae were reared on a diet at $25^{\circ} \mathrm{C}$ and were examined to determine whether they could develop to the next stadium. In other set of experiments, $0.1 \%$ Polyoxin AL was used. Control larvae were immersed in DW.

Oral application of Polyoxin B st., polyoxin D, and nikkomycin $\mathrm{Z}$. Polyoxin $\mathrm{D}$ and nikkomycin $\mathrm{Z}$ were added to the diet at $0.015 \%$, and 0.005 and $0.015 \%$, respectively. Polyoxin B st. was added to the diet at $0.0052,0.017$, and $0.052 \%$, which resulted in a net concentration of the active component, polyoxin $\mathrm{B}$, at $0.0015,0.005$, and $0.015 \%$, respectively. Pharate-3rd stadium S. litura larvae were reared on the diet with those chemicals at $25^{\circ} \mathrm{C}$. After $48 \mathrm{~h}$, they were switched to a normal diet and reared for additional $4 \mathrm{~d}$. The larval devel- opment was followed as mentioned above.

Hypodermic injection of Polyoxin B st. and polyoxin D. Pharate-6th stadium $S$. litura larvae were reared with a diet at $25^{\circ} \mathrm{C}$. After $48 \mathrm{~h}$, larvae from 24 to $48 \mathrm{~h}$ into the 6 th stadium were obtained. Polyoxin B st. and polyoxin D were dissolved in DW at $0.1 \%(\mathrm{wt} / \mathrm{vol})$ and injected into the larvae at $25 \mu \mathrm{l} /$ larva hypodermically with a syringe. Newly exuviated 4th stadium $B$. mori larvae were fed with a diet at $25^{\circ} \mathrm{C}$. Larvae at 72 and $96 \mathrm{~h}$ into the 4th stadium were injected with those chemicals similarly. These larvae were reared on a diet without those chemicals, and their development was followed as mentioned above.

The number of specimens used for each assay is shown in each figure unless otherwise mentioned in the text. The chi-square test was used as needed.

\section{RESULTS}

\section{Dose response of lepidopteran species to Poly-} oxin AL

The number of larvae that developed to the 4th and 5th stadiums is shown in Table 1. All the larvae used in this assay developed to the pharate-4th stadium, in which they showed a normal appearance, but thereafter their development differed depending on the dose of chemical applied. In $S$. litura, almost all larvae developed normally at $0.01 \%$. At $0.03 \%$, almost all larvae molted to the 4th stadium and then failed to grow. These larvae tried to eat the diet provided but could not feed on it, which resulted in death by starvation. At $0.1 \%$, all larvae failed to molt. Larval development stopped at the pharate stage or during ecdysis. In $M$. brassicae and $M$. separata, all larvae died at 0.1 and $0.3 \%$, respectively. B. mori was more resistant than the others. Even at $0.3 \%$, only 3 specimens failed to molt. A significant difference in mortality was not detected at 0 (control) and $0.3 \%$ by chisquare test $(\alpha=0.05)$.

\section{Toxicity of Polyoxin AL on 3rd, 4th, 5th, and 6th stadium $S$. litura larvae}

The effects of Polyoxin AL are shown in Table 2. Rearing the 3rd, 4th, and 5th stadium larvae for $48 \mathrm{~h}$ with the fungicide resulted in an inhibition of development in the same manner as observed in the above-mentioned experiment. When larvae were fed with the fungicide for only $24 \mathrm{~h}$, some lar- 
Table 1. Dose-effect of Polyoxin AL added in diet on the development of S. litura, M. separata, M. brassicae and B. mori

\begin{tabular}{|c|c|c|c|c|}
\hline \multirow{2}{*}{ Species $^{\mathrm{a}}$} & \multirow{2}{*}{$\begin{array}{c}\% \text { of Polyoxin } \\
\text { AL in diet }\end{array}$} & \multirow{2}{*}{$\begin{array}{l}\text { No. of larvae used } \\
\text { in each assay }\end{array}$} & \multicolumn{2}{|c|}{ No. of larvae that developed to the indicated stadium } \\
\hline & & & 4 th & 5 th \\
\hline \multirow[t]{4}{*}{ S. litura } & 0 (control) & 30 & 30 & 30 \\
\hline & 0.01 & 30 & 30 & 29 \\
\hline & 0.03 & 30 & 29 & 0 \\
\hline & 0.1 & 30 & 0 & 0 \\
\hline \multirow[t]{3}{*}{ M. separata } & 0 (control) & 30 & 30 & 30 \\
\hline & 0.03 & 30 & 30 & 29 \\
\hline & 0.1 & 30 & 9 & 0 \\
\hline \multirow[t]{4}{*}{ M. brassicae } & 0 (control) & 30 & 30 & 30 \\
\hline & 0.03 & 30 & 30 & 30 \\
\hline & 0.1 & 30 & 12 & 11 \\
\hline & 0.3 & 30 & 0 & 0 \\
\hline \multirow[t]{3}{*}{ B. mori } & 0 (control) & 30 & 30 & 30 \\
\hline & 0.1 & 30 & 30 & 30 \\
\hline & 0.3 & 30 & 27 & 27 \\
\hline
\end{tabular}

a 3 rd stadium larvae were used for all species.

Table 2. Effects of $0.1 \%$ Polyoxin AL added in diet on the larval development of S. litura

\begin{tabular}{|c|c|c|c|c|}
\hline \multirow{2}{*}{$\begin{array}{l}\text { Larval stadium } \\
\text { feeding on a diet } \\
\text { with Polyoxin AL }\end{array}$} & \multirow{2}{*}{$\begin{array}{l}\text { Duration (h) while } \\
\text { larvae fed on a diet } \\
\text { with Polyoxin AL }\end{array}$} & \multirow{2}{*}{$\begin{array}{l}\text { No. of larvae used } \\
\text { in each assay }\end{array}$} & \multicolumn{2}{|c|}{ No. of larvae that developed to the indicated stage } \\
\hline & & & Next stadium & Stadium after the next \\
\hline \multirow[t]{3}{*}{3} & control $^{\mathrm{a}}$ & 50 & 50 & 50 \\
\hline & 24 & 50 & 47 & 11 \\
\hline & 48 & 50 & 2 & 0 \\
\hline \multirow[t]{3}{*}{4} & control & 50 & 50 & 50 \\
\hline & 24 & 50 & 28 & 14 \\
\hline & 48 & 50 & 0 & 0 \\
\hline \multirow[t]{3}{*}{5} & control & 25 & 25 & 25 \\
\hline & 24 & 25 & 24 & 14 \\
\hline & 48 & 25 & 16 & 0 \\
\hline \multirow[t]{3}{*}{$6^{\mathrm{b}}$} & control & 20 & 20 & $-^{c}$ \\
\hline & 24 & 20 & 14 & - \\
\hline & 48 & 20 & 0 & - \\
\hline
\end{tabular}

${ }^{\text {a }}$ Control larvae were fed with a diet without Polyoxin AL.

${ }^{\mathrm{b}}$ Number of larvae that pupated was examined.

${ }^{\mathrm{c}}$ Not valid for these experimental conditions.

vae survived. Some of the larvae that molted to the next stadium moved around and tried to eat the diet provided but could not feed on it, which resulted in death by starvation. The remaining molting larvae fed on the diet and developed to the stadium after the next and continued normal development. Sixth stadium larvae that fed on Polyoxin AL for $48 \mathrm{~h}$ failed to pupate normally. Larvae with a prolapsed hindgut, larvae whose development stopped at the prepupal stage, and pupae that were morphologi- cally abnormal were observed (see Tateishi et al., 1993). Some of the larvae exposed to the fungicide for $24 \mathrm{~h}$ pupated with normal appearance.

\section{$\mathrm{LC}_{50}$ of Polyoxin AL}

The $\mathrm{LC}_{50}$ of Polyoxin AL after being orally applied to $S$. litura 3 rd stadium larvae was examined in two replicates. LC $_{50}$ values of 0.0203 and $0.0187 \%$ were obtained, whose $95 \%$ confidence limits were from 0.0194 to $0.0212 \%$ (degree of 
freedom $=7$ ) and from 0.0172 to $0.0200 \%$ (degree of freedom $=4$ ), respectively. The difference in these $\mathrm{LC}_{50}$ values was not significant because their 95\% confidence limits overlapped.

\section{Morphology of $S$. litura after the oral applica- tion of Polyoxin AL}

At $48 \mathrm{~h}$, both the control and experimental larvae developed to the pharate-4th stadium, whose external appearances were the same. Internally, however, differences in cuticular production were ob- served. The control larvae formed a new cuticle on the epidermal cells and the old cuticle dissociated over the new (Fig. 1a). In the larvae that fed on $0.3 \%$ Polyoxin AL, the old cuticle dissociated from the epidermal cells and the molting fluid was under the cuticle (Fig. 1b). A new cuticle, however, was not produced at this time. At $72 \mathrm{~h}$, the control larvae developed to the 4th stadium, and the old cuticle had already been exuviated (Fig. 1c). The larvae treated with Polyoxin AL appeared to still be in the pharate-4th stadium. Epicuticle, the outermost

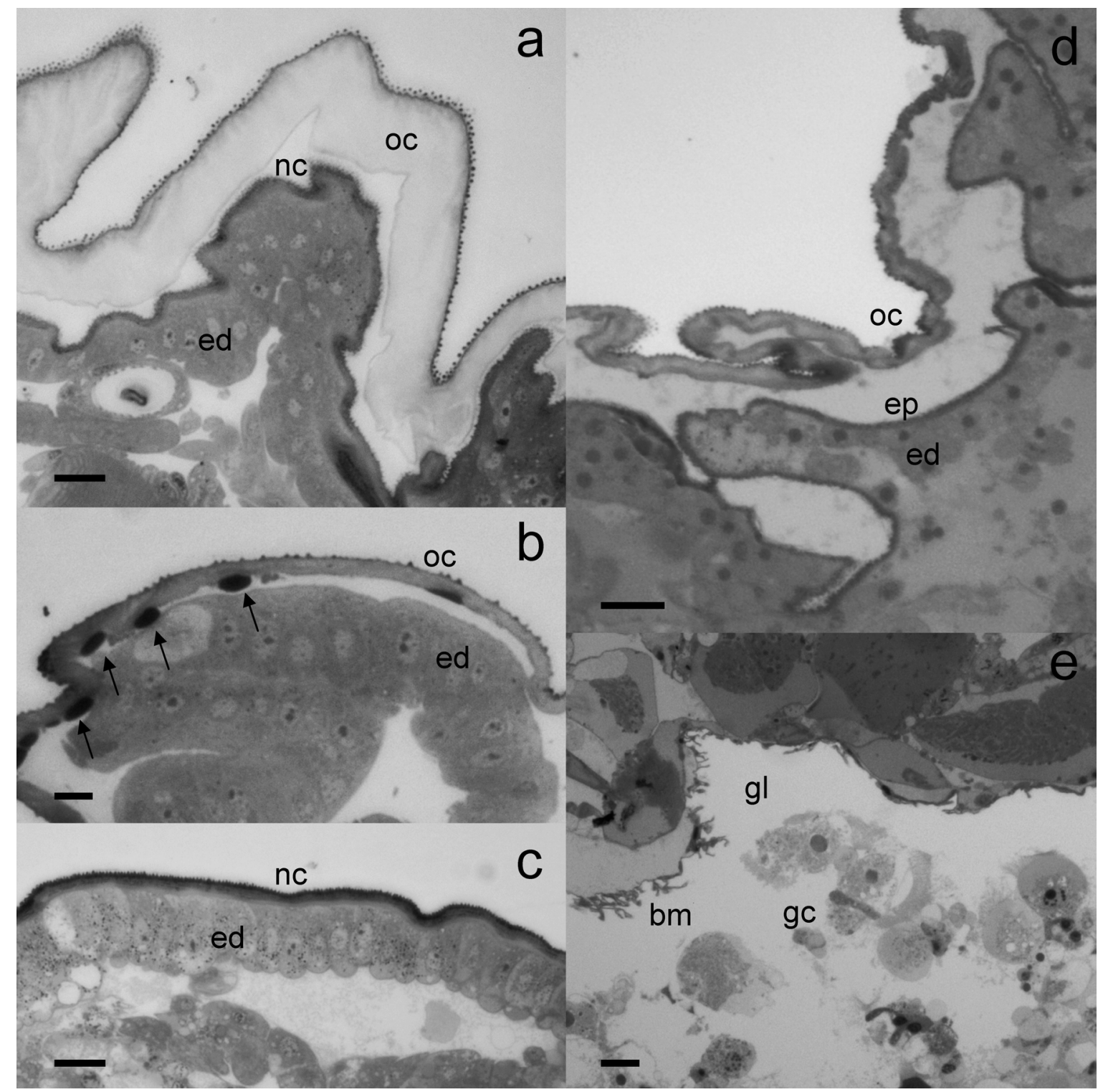

Fig. 1. Internal morphologies of $S$. litura: a, control larval epidermis in pharate-4th stadium at $48 \mathrm{~h}$; b, epidermis of a larva feeding on $0.3 \%$ Polyoxin AL at $48 \mathrm{~h}$ that is in pharate-4th stadium; c, control larval epidermis molting to 4 th stadium at $72 \mathrm{~h}$; $\mathrm{d}$, epidermis of a larva feeding on $0.3 \%$ Polyoxin $\mathrm{AL}$ at $72 \mathrm{~h}$ that appears to still be in pharate-4th stadium; e, midgut tissue of a larva feeding on $0.3 \%$ Polyoxin AL at $72 \mathrm{~h}$ that appears to still be in pharate- 4 th stadium. arrow, molting fluid; bm, basement membrane; ed, epidermal cell; ep, epicuticle; gc, gut cell; gl, gut lumen; nc, new cuticle; oc, old cuticle. Scale bar: $20 \mu \mathrm{m}$. 
layer of the cuticle, was visible over the epidermal cells, although the procuticle was not observed under the epicuticle (Fig. 1d). At this stage, the midgut showed striking morphological changes. Midgut cells dissociated from the basement membrane, an extracellular matrix surrounding these cells, and fell into the lumen (Fig. 1e), where the basement membrane was exposed. In the control larvae in the pharate- 4 th stadium at $48 \mathrm{~h}$, some midgut cells dissociated and fell into the lumen, and new cells were supplied from stem cells regenerating the tissue (data not shown).

\section{Relationship between the lethal effect of Poly- oxin AL and development}

Forty-eight specimens that fed on Polyoxin AL during the latter half in the 3rd stadium failed to molt. Their development stopped at the pharate-4th stadium. The other two specimens molted to the 4th stadium but failed to grow and finally died by starvation. Of the control larvae, 45 specimens molted to the 4th stadium. Sixteen specimens developed further and the other 29 failed to grow after ecdysis and eventually died by starvation. Five larvae died at the pharate-4th stadium. A significant difference in mortality was detected between the control and the experimental larvae by chi-square test $(\alpha=0.05)$.

\section{Body surface treatment with Polyoxin AL}

The effects of body surface treatment with $1 \%$ Polyoxin AL on the molting of S. litura and B. mori are shown in Table 3. In $S$. litura, molting was inhibited effectively when the larvae from 24 to $48 \mathrm{~h}$ into the 3rd stadium were treated. In B. mori, molting was inhibited only when the larvae were treated at $72 \mathrm{~h}$ into the $3 \mathrm{rd}$ stadium. These larvae died at the pharate-4th stadium or during ecdysis. Treatment with $0.1 \%$ Polyoxin AL had no effect on both species (data not shown).

\section{Oral application of Polyoxin B st., polyoxin D, and nikkomycin $\mathrm{Z}$}

The effects of oral application of the antibiotics on the development of S. litura are shown in Table 4. In the case of Polyoxin B st., the net concentration of polyoxin $\mathrm{B}$, an active component in the product, in diet is shown in the table. All larvae developed to the pharate-4th stadium with a normal appearance, regardless of the antibiotic used. At $0.005 \%$ polyoxin $\mathrm{B}$, some of the larvae molted to the 4th stadium but failed to grow. The larvae tried to eat the diet but could not feed on it and eventually died by starvation. The others died at the pharate-4th stadium or during ecdysis. At $0.015 \%$ polyoxin B, all larvae died at the pharate-4th stadium. Polyoxin $\mathrm{D}$ had no effect on the development, even at $0.015 \%$. Nikkomycin Z inhibited the development at $0.015 \%$, but had no effect at $0.005 \%$.

\section{Hypodermic injection of Polyoxin B st. and poly- oxin D}

The effects of the hypodermic injection of the antibiotics are shown in Table 5. In S. litura, both antibiotics inhibited pupation. The injection of DW had no effect. The larvae injected with the antibiotics developed to the prepupal stage and then

Table 3. Inhibition of larval molt of $S$. litura and B. mori by dipping the larvae in $1 \%$ Polyoxin AL solution

\begin{tabular}{|c|c|c|c|c|c|}
\hline \multirow{2}{*}{ Species } & \multirow{2}{*}{$\begin{array}{c}\text { Stage in 3rd stadium }(\mathrm{h}) \text { at } \\
\text { which the larvae were treated }\end{array}$} & \multirow{2}{*}{$\begin{array}{l}\text { No. of larvae used } \\
\text { in each assay }\end{array}$} & \multicolumn{2}{|c|}{$\begin{array}{l}\text { No. of larvae that failed in } \\
\text { molting to the next stadium }\end{array}$} & \multirow{2}{*}{ Chi-square test ${ }^{b}$} \\
\hline & & & Control $^{\mathrm{a}}$ & Treated & \\
\hline \multirow[t]{2}{*}{ S. litura } & $0-24$ & 30 & 0 & 1 & $\mathrm{~ns}$ \\
\hline & 24-48 (pharate-4th stadium) & 30 & 0 & 20 & $\mathrm{~s}$ \\
\hline \multirow[t]{5}{*}{ B. mori } & 0 & 30 & 0 & 0 & $-^{c}$ \\
\hline & 24 & 30 & 0 & 0 & - \\
\hline & 48 & 30 & 0 & 1 & ns \\
\hline & 72 & 30 & 0 & 19 & $\mathrm{~s}$ \\
\hline & 96 (pharate-4th stadium) & 30 & 0 & 4 & ns \\
\hline
\end{tabular}

\footnotetext{
${ }^{\text {a }}$ Control larvae were dipped in DW.

${ }^{\mathrm{b}}$ The difference between the control and the treated was analyzed $(\alpha=0.05)$; ns: not significant, s: significant.

${ }^{\mathrm{c}}$ Not tested.
} 
Table 4. Effects of oral application of Polyoxin B st., polyoxin D and nikkomycin Z on the larval development of S. litura

\begin{tabular}{|c|c|c|c|c|}
\hline \multirow{2}{*}{ Chemical } & \multirow{2}{*}{$\begin{array}{l}\text { Concentration of the } \\
\text { chemical in diet }(\%)\end{array}$} & \multirow{2}{*}{$\begin{array}{l}\text { No. of larvae used } \\
\text { in each assay }\end{array}$} & \multicolumn{2}{|c|}{$\begin{array}{l}\text { No. of larvae that developed to the } \\
\text { indicated larval stadium }{ }^{\mathrm{a}}\end{array}$} \\
\hline & & & 4 th & 5 th \\
\hline \multirow[t]{4}{*}{ Polyoxin B st. } & $0^{\mathrm{b}}$ (control) & 30 & 30 & 30 \\
\hline & 0.0015 & 30 & 29 & 28 \\
\hline & 0.005 & 30 & 12 & 0 \\
\hline & 0.015 & 30 & 0 & 0 \\
\hline \multirow[t]{2}{*}{ Polyoxin D } & 0 (control) & 30 & 30 & 30 \\
\hline & 0.015 & 30 & 30 & 30 \\
\hline \multirow[t]{3}{*}{ Nikkomycin Z } & 0 (control) & 30 & 30 & 30 \\
\hline & 0.005 & 30 & 30 & 30 \\
\hline & 0.015 & 30 & 4 & 0 \\
\hline
\end{tabular}

a 3 rd stadium larvae were fed with the chemical added in diet.

${ }^{\mathrm{b}}$ Net concentration of polyoxin B, an active component in Polyoxin B st., was presented.

Table 5. Inhibitory effects of hypodermic injection of Polyoxin B st. and polyoxin D on the pupation or larval molt of $S$. litura and $B$. mori

\begin{tabular}{|c|c|c|c|c|c|}
\hline \multirow{2}{*}{ Species } & \multirow{2}{*}{$\begin{array}{l}\text { Stage at which the } \\
\text { chemical was injected }\end{array}$} & \multirow{2}{*}{$\begin{array}{l}\text { Chemical } \\
\text { injected }\end{array}$} & \multirow{2}{*}{$\begin{array}{c}\text { No. of larvae } \\
\text { used in } \\
\text { each assay }\end{array}$} & \multicolumn{2}{|c|}{$\begin{array}{l}\text { No. of larvae that failed in development } \\
\text { to the indicated developmental stage }\end{array}$} \\
\hline & & & & Pupa & 5th stadium larvae \\
\hline \multirow[t]{3}{*}{ S. litura } & 24-48 $\mathrm{h}$ into 6 th stadium & DW (control) & 30 & 0 & $-^{\mathrm{a}}$ \\
\hline & & $0.1 \%$ Polyoxin B st. & 30 & 28 & - \\
\hline & & $0.1 \%$ polyoxin $\mathrm{D}$ & 30 & 22 & - \\
\hline \multirow[t]{6}{*}{ B. mori } & $72 \mathrm{~h}$ into 4 th stadium & DW (control) & 30 & - & 0 \\
\hline & & $0.1 \%$ Polyoxin B st. & 30 & - & 13 \\
\hline & & $0.1 \%$ polyoxin $\mathrm{D}$ & 30 & - & 0 \\
\hline & $96 \mathrm{~h}$ into 4 th stadium & DW (control) & 30 & - & 1 \\
\hline & & $0.1 \%$ Polyoxin B st. & 30 & - & 26 \\
\hline & & $0.1 \%$ polyoxin $\mathrm{D}$ & 30 & - & 1 \\
\hline
\end{tabular}

${ }^{\mathrm{a}}$ Not valid for these experimental conditions.

failed to pupate. The difference in mortality between Polyoxin B st. and polyoxin D was not significant by chi-square test $(\alpha=0.05)$. In B. mori, polyoxin D did not inhibit molting, although Polyoxin B st. effectively inhibited molting.

All the above experiments were replicated two to four times and similar results were obtained.

\section{DISCUSSION}

It was shown that Polyoxin AL, an agricultural fungicide containing polyoxin B, killed M. brassicae, $M$. separata, and $S$. litura larvae when applied orally. Polyoxin B st. killed the $S$. litura larvae when applied orally and hypodermically. Polyoxin
AL treatment on the body surface also killed $S$. litura and B. mori larvae. These results indicate that polyoxin B exerts toxicity on insects, especially on $S$. litura, irrespective of the application route. It just should be borne in mind that the Polyoxin B st. consists of $29 \%$ polyoxin B and $71 \%$ impurities whose constituents are not identified. The effect of the impurities on insects was not examined in the present study.

Oral toxicity is especially important for pest control. The following three characteristics of killing were shown: 1) Larvae feeding on Polyoxin $\mathrm{AL}$ grew and developed to the next pharate stadium, but thereafter failed to molt, which was shown in M. brassicae, M. separata, and S. litura; 
2) S. litura larvae orally treated with Polyoxin AL produced only the epicuticle, which is the outermost layer of the epidermal cuticle and lacks chitin. Procuticle, which contains chitin, was not produced under the epicuticle; and 3) Oral application and body surface treatment of $S$. litura with Polyoxin AL was effective only when applied close to the molting stage. In insects, chitinous cuticle of the next stadium epidermis is produced anew before molting by the action of chitin synthase, which is regulated by the endocrine system (Calvez et al., 1976; Kiguchi and Agui, 1981; Nijhout, 1994; Merzendorfer and Zimoch, 2003; Truman, 2005). Polyoxins are the analogous chemicals of UDP- $N$ acetylglucosamine, the substrate of chitin synthase (Hori et al., 1971). Thus, it was suggested that Polyoxin AL killed the larvae by inhibiting the chitin synthase involved in epidermal cuticle production. Polyoxin AL exerted a destructive effect not only on the epidermis but also on the midgut of $S$. litura. It was not determined whether the destruction of the midgut was directly caused by the inhibition of chitin synthase or whether it was an indirect effect resulting from the disintegration of the developmental process. Further studies are required to clarify the cause.

$S$. litura is polyphagous and causes serious damage to many crops. This insect was more sensitive to Polyoxin AL than the other species used in this study. Polyoxin AL killed $S$. litura larvae at a level of $0.03 \%$ in diet when fed continuously. Killing the pest at lower dosages would be required for practical use as a pesticide. Polyoxin B, an active component in Polyoxin AL, will serve as a lead chemical in the development of more effective ones. In this context, the ineffectiveness of orally applied polyoxin D is of interest. Polyoxin B has an alcohol group $\left(\mathrm{CH}_{2} \mathrm{OH}\right)$ at $\mathrm{C} 5$ position of the uracil moiety, and its counterpart on polyoxin D is a carboxyl group (COOH) (Hori et al., 1971). Comparative studies of orally applied polyoxin B and D on their absorption, metabolism, persistence, and excretion will provide knowledge that will lead to the development of a more effective insecticidal agent. Polyoxin $B$ is of interest as a lead chemical because of its lack of adverse effects on the silkworm B. mori when applied orally. The development of a chemical with low toxicity to $B$. mori but high toxicity to other pest insects is desired. Such a chemical will be used in and near a mulberry farm for sericul- ture. Nikkomycin $\mathrm{Z}$ is also a candidate for a lead chemical because its oral application has been shown to kill $S$. litura.

The toxicity of polyoxin B and D in S. litura was different from that in B. mori. In S. litura, both the polyoxins inhibited metamorphosis when injected hypodermically. In B. mori, only polyoxin B was effective, which was an unexpected result. Many studies have shown that polyoxin D inhibits insect chitin synthesis when directly applied to the tissue by hypodermic injection or by in vitro tissue culture (see Introduction). The mechanism responsible for these different responses of $S$. litura and $B$. mori is unknown. The molecular affinities of these polyoxins to the chitin synthase of these insects should be studied. This will serve as a good model for studying the species specificity of chemical toxicity.

\section{REFERENCES}

Becker, B. (1980) Effects of polyoxin D on in vitro synthesis of peritrophic membranes in Calliphora erythrochephala. Insect Biochem. 10: 101-106.

Binnington, K. C. (1985) Ultrastructural changes in the cuticle of the sheep blowfly, Lucilia, induced by certain insecticides and biological inhibitors. Tissue Cell 17: 131-140

Calvez, B., M. Hirn and M. De Reggi (1976) Ecdysone changes in the haemolymph of two silkworms (Bombyx mori and Philosamia cynthia) during larval and pupal development. FEBS Lett. 71: 57-61.

Cohen, E. (1987) Chitin biochemistry: synthesis and inhibition. Ann. Rev. Entomol. 32: 71-93.

Cohen, E. and J. E. Casida (1982) Properties and inhibition of insect integumental chitin synthetase. Pestic. Biochem. Physiol. 17: 301-306.

Decker, H., H. Zähner, H. Heitsch, W. A. König and H. P. Fiedler (1991) Structure-activity relationships of nikkomycins. J. Gen. Microbiol. 137: 1805-1813.

Gelman, D. B. and A. Borkovec (1986) The pharate adult clasper as a tool for measuring chitin synthesis and for identifying new chitin synthesis inhibitors. Comp. Biochem. Physiol. 85C: 193-197.

Gijswijt, M. J., D. H. Deul and B. J. De Jong (1979) Inhibition of chitin synthesis by benzoyl-phenylurea insecticides, III. Similarity in action in Pieris brassicae (L.) with polyoxin D. Pestic. Biochem. Physiol. 12: 87-94.

Holst, H., D. Malissiovas and H. Schmutterer (1978) Wirkungen eines chitinsynthesehemmenden Antibiotikums auf Spinnmilben und Insekten. Mitt. Dtsch. Ges. Allg. Angew. Entomol. 1: 143-146.

Hori, M., K. Kakiki, S. Suzuki and T. Misato (1971) Studies on the mode of action of polyoxins. Part III. Relation of polyoxin structure to chitin synthetase inhibition. Agric. Biol. Sci. 35: 1280-1291. 
Kaska, H. M., R. T. Mayer, B. A. Sowa, R. W. Meola and D. L. Coopage (1980) Chitin synthesis in Heliothis zea (Boddie) pupae and inhibition by chitin synthesis inhibitors. Southw. Entomologist 5: 139-143.

Kiguchi, K. and N. Agui (1981) Ecdysteroid levels and developmental events during larval moulting in the silkworm, Bombyx mori. J. Insect Physiol. 27: 805-812.

Kitahara, K., Y. Nakagawa, T. Nishioka and T. Fujita (1983) Cultured integument of Chilo suppressalis as a bioassay system of insect growth regulators. Agric. Biol. Chem. 47: 1583-1589.

Mayer, R. T., S. M. Meola, D. C. Coppage and J. R. DeLoach (1980a) Utilization of imaginal tissues from pupae of the stable fly for the study of chitin synthesis and screening of chitin synthesis inhibitors. J. Econ. Entomol. 73: $76-80$.

Mayer, R. T., A. C. Chen and J. R. DeLoach (1980b) Characterization of a chitin synthase from the stable fly, Stomoxys calcitrans (L.). Insect Biochem. 10: 549-556.

Merzendorfer, H. and L. Zimock (2003) Chitin metabolism in insects: structure, function and regulation of chitin synthases and chitinases. J. Exp. Biol. 206: 4393-4412.

Mothes, U. and K. A. Seitz (1982) Action of the microbial metabolite and chitin synthesis inhibitor nikkomycin on the mite Tetranychus urticae; an electron microscope study. Pestic. Sci. 13: 426-441.

Nakagawa, Y., F. Matsumura and Y. Hashino (1993) Effect of diflubenzuron on incorporation of $\left[{ }^{3} \mathrm{H}\right]-\mathrm{N}$-acetylglucosamine $\left(\left[{ }^{3} \mathrm{H}\right] \mathrm{NAGA}\right)$ into chitin in the intact integument from the newly molted American cockroach Periplaneta americana. Comp. Biochem. Physiol. 106C: $711-715$.

Nijhout, H. F. (1994) Insect Hormones. Princeton Univ. Press, Princeton. 267 pp.

Nishioka, T., T. Fujita and M. Nakajima (1979) Effect of chitin synthesis inhibitors on cuticle formation of the cultured integument of Chilo suppressalis. J. Pestic. Sci. 4:
$367-374$

Schlüter, U. (1982) Ultrastructural evidence for inhibition of chitin synthesis by nikkomycin. Roux's Arch. Dev. Biol. 191: 205-207.

Shahabuddin, M., T. Kaidoh, M. Aikawa and D. C. Kaslow (1995) Plasmodium gallinaceum: mosquito peritrophic matrix and the parasite-vector compatibility. Exp. Parasitol. 81: 386-393.

Sowa, B. A. and E. P. Marks (1975) An in vitro system for the quantitative measurement of chitin synthesis in the cockroach: inhibition by TH 6040 and polyoxin D. Insect Biochem. 5: 855-859.

Tateishi, K., M. Kiuchi and S. Takeda (1993) New cuticle formation and molt inhibition by RH-5859 in the common cutworm, Spodoptera litura (Lepidoptera: Noctuidae). Appl. Entomol. Zool. 28: 177-184.

Tellam, R. L. and C. Eisemann (2000) Chitin is only a minor component of the peritrophic matrix from larvae of Lucilia cuprina. Insect Biochem. Molec. Biol. 30: 1189-1201.

Tellam, R. L., T. Vuocolo, S. E. Johnson, J. Jarmey and R. D. Pearson (2000) Insect chitin synthase: cDNA sequence, gene organization and expression. Eur. J. Biochem. 267: 6025-6042.

Truman, J. W. (2005) Hormonal control of insect ecdysis: endocrine cascades for coordinating behavior with physiology. Vitam. Horm. 73: 1-30.

Turnbull, I. F. and A. J. Howells (1982) Effects of several larvicidal components on chitin biosynthesis by isolated larval integument of the sheep blowfly Lucilia cuprina. Aust. J. Biol. Sci. 35: 491-503.

van Eck, W. H. (1979) Mode of action of two benzoylphenyl ureas as inhibitors of chitin synthesis in insects. Insect Biochem. 9: 295-300.

Vardanis, A. (1978) Polyoxin fungicides: demonstration of insecticidal activity due to inhibition of chitin synthesis. Experientia 34: 228-229. 